\title{
Article \\ Incentive Schemes Increase Risky Behavior in a Safety-Critical Working Task: An Experimental Comparison in a Simulated High-Reliability Organization
}

\author{
Sebastian Brandhorst*(D) and Annette Kluge (D) \\ Chair of Business Psychology, Ruhr-Universität Bochum, 44780 Bochum, Germany; annette.kluge@rub.de \\ * Correspondence: sebastian.brandhorst@rub.de; Tel.: +49-234-32-24608
}

check for updates

Citation: Brandhorst, S.; Kluge, A. Incentive Schemes Increase Risky Behavior in a Safety-Critical Working Task: An Experimental Comparison in a Simulated High-Reliability Organization. Safety 2022, 8, 17. https://doi.org/10.3390/ safety 8010017

Academic Editor: Raphael Grzebieta

Received: 29 December 2021

Accepted: 23 February 2022

Published: 4 March 2022

Publisher's Note: MDPI stays neutral with regard to jurisdictional claims in published maps and institutional affiliations.

Copyright: (C) 2022 by the authors. Licensee MDPI, Basel, Switzerland. This article is an open access article distributed under the terms and conditions of the Creative Commons Attribution (CC BY) license (https:// creativecommons.org/licenses/by/ $4.0 /)$.

\begin{abstract}
As financial incentive schemes have the tendency to increase risky behavior, we analyzed their effect on rule-related behavior in a safety-critical task. We compared risky behavior (in terms of the amount of rule violations) between three payment condition: continuous, up-front, and bonus pay. Fifty-nine participants were trained as production personnel to conduct a start-up procedure of a simulated wastewater treatment plant, representing a high reliability organization. During the 5-h experimental study, risky behavior could have been applied 48 times while building a simulated production year. The results show that the conditions with an incentive scheme (up-front and bonus pay) led to significantly more rule violations than the condition with continuous payment without an incentive scheme. Our study highlights the general increased risk effect of incentive schemes and provides a starting point for industries to assess their implicit and explicit incentive schemes.
\end{abstract}

Keywords: rule violations; behavior-based safety management; evidence-based management

\section{Introduction: Some Evidence on Incentives and Risky Behavior}

In 2010, the oil rig Deepwater Horizon exploded, and the board members of the operating company, Transocean, received multi-million-dollar bonus payments for the safest year in the company's history. However, 9 of the 11 fatalities were their own employees [1]. When, in 2015, the judicial consequences of the manipulation of emission data of the world's largest automobile company caused an annual loss of 4 billion euros. The board members received a total of 5.7 million euros in bonus payments [2]. However, bonus contracts have been criticized since before board members sank billions and oil rigs. The biggest damage caused by incentive schemes is probably the financial crisis starting in 2007, with an estimated 22 trillion US dollars in the US alone [3]. There is also some empirical evidence from the financial sector of the influence of incentives on risk-taking behavior, which we will touch upon in the following section. As early as 1975, Stiglitz discussed the importance of rewards and their relationship with risk-taking behavior [4]. According to current studies, the question is not whether profit-oriented performance-based incentive schemes influence risk choice behavior, but to what extent [5].

Since risky work behavior is one of the main causes of occupational accidents [6], the purpose of this paper is to transfer the research approach of incentive consequences to the influence of safety-related rule violations in risky work contexts. In the following, we compile the empirical effects of incentives on risk-related behavior. We then differentiate between the different forms of incentive systems. In light of these findings, we turn our study to the question of the extent to which performance-based reward systems affect people's willingness to violate safety-related rules.

\subsection{Effect of Incentives on Risk Taking}

The increase of risk-related behavior by incentive schemes can become out of hand and lead to excessive risk, as the financial crisis at the beginning of the century made 
clear [5]. Bonus contracts have the very specific function of guiding behavior toward desired organizational goals and controlling the risk propensity of individuals, in this case board members and managers [7]. Regardless of actual risks, there is a difference between the risk propensity of managers and shareholders. Shareholders can divide their investments among different companies, while managers are tied to one company. Managers are assumed to be less inclined to take risks than shareholders. As a result, the latter have an interest in increasing the former's risk behavior for the purpose of maximizing profits. The tool for this is incentive schemes [8]. A comparison of incentive schemes in different countries shows that the design of these incentives depends, among other things, on how well employees in wage employment are protected in the event of unemployment (here, by management failure). The more "convenient" national unemployment insurance systems are, the more incentive schemes push managers toward taking more risks [9]. The design of risk-promoting incentives seems to be an advantage for shareholders in the first place. The effect on employees in terms of the role model function of management is less considered in these incentive schemes. The risks of board members are of a financial nature, whereas the risks of employees in everyday work relate to their health and lives [7].

Employees use the behavior of managers and supervisors to guide their own attitudes regarding risk-related behavior [10]. Increased risk-taking by employees is preceded by their perception that the organization (as represented by managers) is lenient when dealing with bad decisions. However, in the context of safety-critical activities, this could negatively influence the safety-related behavior of employees. The alleged productivity advantage [10] then actually has observable catastrophic consequences. The notion of the invisible hand regulating the market and, consequently, incentive schemes does not apply to occupational safety. This is why government-regulated occupational safety measures are necessary [11].

In our study, we consider the effects of financial performance-based incentive schemes on risky decision-making operationalized in terms of safety-related work behavior. The purpose of this study is to investigate the risk-increasing effect of financial performance-based incentives on safety-related behavior. As a research question, we transfer the managerial perspective of incentive schemes to a risk-increasing effect on safety-related activities. In the following, we discuss forms of incentive scheme design in order to base our research question on increased risk-taking through incentive schemes among workers in safety-related domains.

\subsection{Incentive Schemes and Risk-Taking Behavior}

Generally speaking, incentives provide the prospect of (positive and valued) consequences that will occur under certain conditions [12]. Thus, incentives have the function of creating wanted or avoiding unwanted situations. In the present context of risky work conditions, where risk-related behavior is perceived as vital, the relationship between incentive schemes and risk-related behavior is discussed. In order to understand this relationship, the prerequisite conditions for risky behavior are summarized. Regarding the prerequisites: (1) the long-term effects of potentially harmful behaviors are not taken into account, (2) information on risks is incomplete or incorrect, and (3) only the positive or negative effects on individuals are considered, but not long-term effects on the individual and others who are indirectly affected [13]. The last aspect of the weighting of information represents the behaviorally relevant starting point of incentive schemes.

The effectiveness of financial incentive schemes includes the following aspects:

(1) Financial resources are redistributed to reduce financial disincentives;

(2) Subsidies can trigger/replace external disincentives;

(3) They can be used to circumvent the effects of bounded rationality, will-power, or self-interest [13].

In the latter, we find the effectiveness of financial incentive schemes with regard to risk-related behavior. In order to support safety-related behavior, it is appropriate to apply incentive schemes with certain performance parameters. 
In summary, incentive research so far generally shows a risk-enhancing effect of performance-related incentive schemes. Nevertheless, incentive schemes that reward safety behavior actually also positively affect work safety. However, there has been no comprehensive investigation of the effects of various incentive schemes on risky behavior in a safety-critical work context with and without conflicting goals. With our study we investigate the effects of explicit financial incentives in the context of up-front and bonus payments compared to non-incentivized continuous pay in a safety-critical work task.

\subsection{General Setup of the Study and Hypotheses}

In the present study, we transfer the findings from different business sectors to the context of safety-related work behavior in a production setting. Due to ethical reasons and to maximize internal validity, we designed a simulation of a special purpose setting [14] to investigate the effects of different incentive programs in a controlled and randomized way.

In the simulated production setting, we implemented the aspects of bonus payments, continuous pay, and up-front pay as independent variables. Risk-taking behavior was operationalized as neglecting to adhere to safety-critical rules in order to protect people and the environment as the dependent variable.

Several studies have already addressed the question of general or specific effects of incentive schemes on performance. Nevertheless, their effect on safety behavior is still a peripheral issue, especially when it comes to the conflict between safety and productivity. Studies already indicate that a conflict between safety and productivity goals undermines safety behavior in favor of task performance [15]. Meanwhile, some studies indicate that incentive schemes that focus on safety-related behavior instead of safety performance (e.g., reported incident rates) have a positive impact on workplace safety [16]. The theoretical assumptions and empirical evidence of the studies cited led to the following hypotheses, which were tested in the controlled experimental study in a simulated production context, which is introduced below.

Hypothesis 1 (H1): In a simulated production setting, participants working under the condition of bonus payments show more risky behavior in terms of not adhering to mandatory safety-related rules than participants receiving continuous pay.

Hypothesis 2 (H2): In a simulated production setting, participants working under the condition of up-front pay show more risky behavior in terms of not adhering to mandatory safety-related rules that participants receiving continuous pay.

Based on the findings of prospect theory [17], punishments have a stronger effect on behavior than rewards; these are referred to as gain and loss perceptions. Here, merely presenting the same facts in either loss-related or gain-related communication is sufficient to influence risk-taking behavior [18]. The influence of loss- and gain-framed compensation models has been much studied, but with mixed results. Performance enhancement under loss-framed conditions has been shown [19-23]. Equally, however, the opposite results regarding the preference of loss-framed compensation models [24-26] and the performance-enhancing effect of gain-framed compensation models [27]. Stock options (as an explicit incentive) have been shown to support higher risk-taking behavior. In this sense, stock options can be understood as a bonus payment promised if certain parameters are achieved [8]. Loss aversion is undermined by stock options, since they exclusively involve participation in profits, but losses are not shared [8].

Up-front payments carry the risk that they will have to be repaid if the targets are not achieved. They represent loss-framing in that compensation already received must be repaid in whole or in part if performance measures are not met. Promised bonuses can be understood as gain-framing. Accordingly, a higher affinity for risk-taking and consequently more rule violations can be expected with up-front payments than the other compensation terms [28]. There is a higher likelihood of risky behaviors under loss-framing. Higher loss 
aversion could further amplify this effect [28]. The findings on the loss and gain framing effect led us to suspect that the incentive schemes themselves differed. In terms of loss framing, the up-front payment scheme leads to a higher willingness to take risks and thus more rule violations than the bonus payment scheme. Thus, our third hypothesis is:

Hypothesis 3 (H3): In a simulated production setting, participants working under the condition of bonus pay show more risky behavior in terms of not adhering to mandatory safety-related rules that participants receiving up-front pay (i.e., more rule violations with bonus pay than with up-front pay).

In summary, risky behavior is assumed under the condition of bonus pay $>$ continuous pay, up-front pay > continuous pay, and up-front pay > bonus pay.

\section{Materials and Methods}

The present study includes a single-factor design in which the factor incentive is divided into 3 levels: continuous compensation, up-front payment, and bonus payment. In total, 59 subjects ( 22 female) aged $\mathrm{M}=21.27$ years $(\mathrm{SD}=3.27$ ) participated in the study. $G^{*}$ Power version 3.1 was used to calculate the optimal sample size to avoid beta error, and we assumed a medium effect size. The calculation recommends a sample size of 251 subjects.

However, weighing the available resources of subjects and subject funds and time, only 20 subjects per condition ( $n=60$ altogether) could be studied. In previous studies [24,29-31], even this sample size showed moderate to strong effects. Only engineering students were approached as participants and accepted for the study. With the subject-related proximity of the sample to the target group of plant operators, we strengthen the external validity of the results. Students were recruited directly with flyers in lectures and on campus. In order not to reveal the experimental object of the incentive-related risk behavior, the participants were recruited under a cover story. Allegedly, the effectiveness of a newly developed training for production personnel was to be evaluated. The target population of the study was exclusively students in engineering and related subjects. All participants were informed of their rights via informed consent. The study was certified by the internal ethics committee as ethically unobjectionable (application number 189, date of decision 18.02.2015). The study was conducted in computer labs at the Ruhr-University Bochum with a group size of 2 to 4 persons. All participants were assigned a prepared place with computer and installed software. At this place, the 5-h study was conducted in one run.

\subsection{Applied Simulation and Experimental Environment}

To investigate the impact of incentive programs on risky behavior in terms of safetyrelated rule violation, we used the wastewater treatment plant simulation (WaTrSim, [32,33]). It simulates the view and function of a control panel of a treatment plant (Figure 1). 


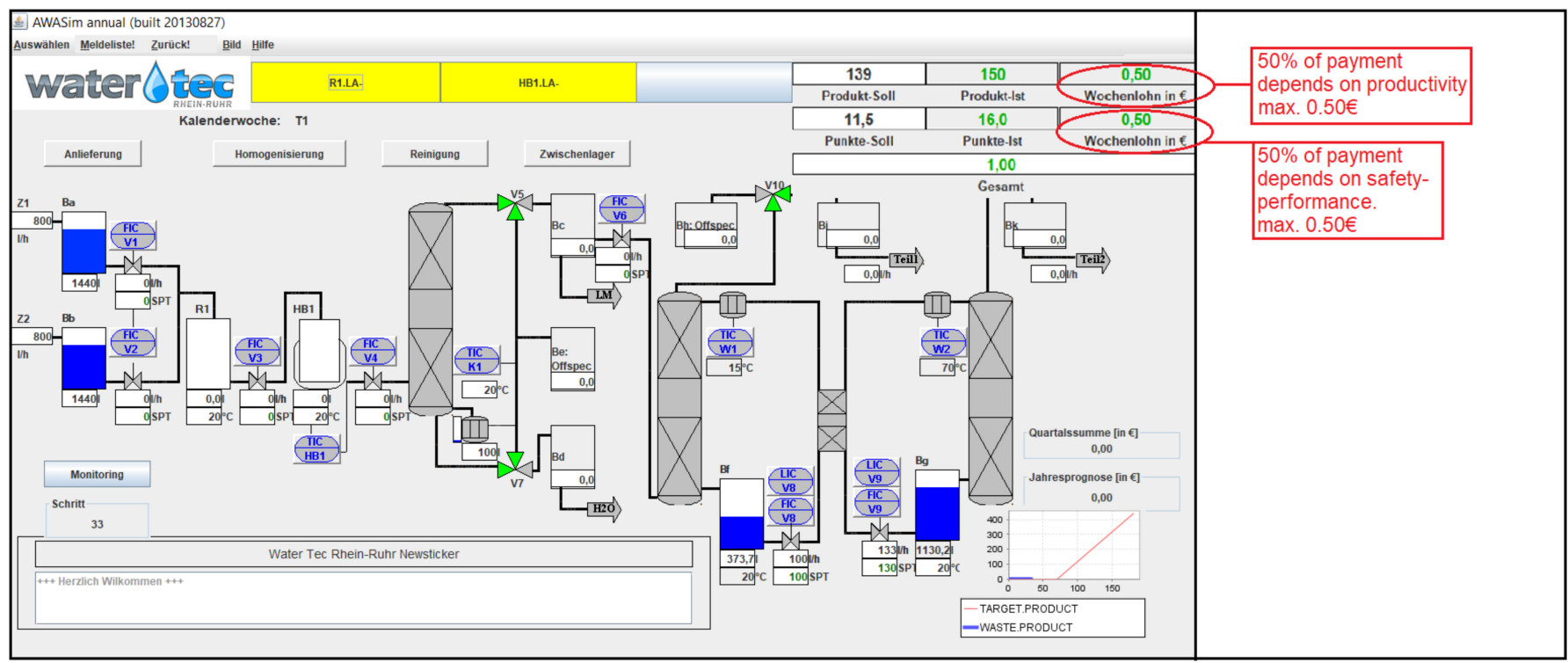

Figure 1. WaTrSim interface, highlighting pay composition.

\subsubsection{Simulation Task and Sequence}

In the experimental setting, we trained the participants as production personnel at this panel, with the task of starting up the plant. The start-up procedures are safety-critical processes in real-world practice. The simulated plant consists of four sections: delivery, homogenization, separation, and product storage. Downstream, there is also a gas washing system. In addition to the plant sections, further information is given on the interface, which is explained below.

In the study, a production year with 48 weeks was simulated. The start-up of the plant must be conducted anew at the beginning of each simulated week. In the course of the study, participants were trained in two procedures. The second, safer procedure is an extension of the first, which means that it is not a fundamentally new procedure but builds on the first one. Having a safe and productive procedure enables operationalization of the trade-off between productivity and safety, in that the earnings are less with the prescribed procedure than the previously learned procedure. This trade-off, however, is negated by the compensation mechanisms, which are explicitly described and explained below.

Before the production phase, participants started up the plant 10 times for training purposes. The following simulated production year was divided into four quarters of 12 simulated weeks each. Each week lasted a total of $2 \mathrm{~min}$ in the production phase and $3 \mathrm{~min}$ in the training phase. In addition to the 10 training runs, the participants ran the plant 58 times.

\subsubsection{Simulation Remuneration and Their Display}

For each simulated production week, depending on their performance, participants received up to $1 €$ compensation, representing in equal parts the productivity and execution of the safe procedure (Figure 1). In order to obtain the maximum pay for productivity, participants needed to achieve a production outcome that satisfied the execution of the mandatory procedure. Safety points are earned by performing the prescribed substeps of the procedure in the correct order with the correct values. This operationalization enables the achievement of maximum pay without a goal conflict between productivity and safety. This achievement can add up to a maximum of $50 €$ in total and represents the participant's compensation. In order to keep track of the progress of one's earnings, this information is provided in the interface (Figure 1).

The interface has a display of the weekly wage (Figure 1, upper right, "Wochenlohn"). This informs the participants about the status of their earnings during the current start-up procedure. In addition, displayed is the quarterly total, which shows the total to date in 
the current quarter (Figure 1, lower right, "Quartalssumme"). The annual forecast display provides information on how much the final pay could be if they reached an average pay (set at 80 cents) in the remaining weeks in addition to what they have earned so far.

\subsection{Independent Variable: Incentive Payment Option}

In principle, participants must earn their remuneration for participation in the experiment by operating the plant. In the second to fourth quarter, the earnings are calculated from two parts: Amount of goods produced; safe operation of the plant. The more goods, the more money and the more correctly the safe procedure is used, the more money. The payment of bonuses is based on an optimal value for quantity of goods and safety. Of these two values, $90 \%$ must be achieved in each case. By meeting this criterion, participants qualify for a bonus payment. If the $90 \%$ criterion is met, the bonus payment is received, and the participant can keep the up-front payment. Table 1 shows an exemplary model of three prototypes of participants' behavior and merit. That is, the rules are either always followed, sometimes followed, or always violated, resulting in the respective merit.

Example: If a participant always executes the standard procedure (Table 1, row "all violations"), which is prohibited at the beginning of the second quarter, he/she could achieve the highest possible production output and payment within the 36 times after start-up the plant. But he/she would not reach the required safety level (90\% threshold) to qualify for the bonus payment. At the same time, because of the continuous violations of the rules during the nine audits, the earnings of the audited week would be deducted (Table 1, column "audit fine"). The different types of standard (risky) and extended (safer) procedures as well as the conducted audits and their consequences are described in the section below. However, as the $90 \%$ criterion prescribes a high rate of safety performance, the incentives cannot be gained by violating the rules all the time.

Table 1. Insights into modeling rule-related behaviors and their effects on pay, including consideration of incentive and non-incentive reward schemes.

\begin{tabular}{|c|c|c|c|}
\hline \multirow[b]{2}{*}{$\begin{array}{c}\text { Theoretically } \\
\text { Possible Operating } \\
\text { Variants }\end{array}$} & \multicolumn{2}{|c|}{ Q2-Q4 (After Intervention) } & \multirow[b]{2}{*}{ Conditions } \\
\hline & $\begin{array}{c}\text { Maximum Merit } \\
\text { Productivity Pay }+ \text { Safety Pay - } \\
\text { Audit Fine }\end{array}$ & $\begin{array}{c}\text { Total Merit }+ \\
4.8 €-12 € \text { from } Q 1\end{array}$ & \\
\hline All compliance & $36 \times 0.50 €+36 \times 0.50 €-0 \times 1.00 €$ & $7.20 €-36.00 €$ & $\begin{array}{l}\text { Continuous pay: } \\
\text { Paid based on what is reached by } \\
\text { applying procedures in each simulated } \\
\text { week, which is total merit. } \\
\text { Up-front pay: }\end{array}$ \\
\hline Mediocre compliance & $36 \times 0.50 €+36 \times 0.40 €-4 \times 1.00 €$ & $7.20 €-28.40 €$ & $\begin{array}{l}50 € \text { paid in advance before production } \\
\text { starts. If } 90 \% \text { criterion is missed, } \\
\text { difference from actual total merit is } \\
\text { reclaimed afterward. }\end{array}$ \\
\hline All violation & $36 \times 0.50 €+36 \times 0.40 €-9 \times 1.00 €$ & $7.20 €-23.40 €$ & $\begin{array}{l}\text { Bonus pay: } \\
\text { If } 90 \% \text { criterion is met, total merit is } \\
\text { rounded up to } 50 € \text {, otherwise only total } \\
\text { merit is paid. }\end{array}$ \\
\hline
\end{tabular}

The Three Factor Levels of Independent Variable

Continuous pay: This serves as the basic model. The remuneration for study participation results from what the participants earned during each production phase on a weekly basis. This can reach $19.20 €$ to $48.00 €$ for all four simulated quarters.

Upfront pay: At the beginning of the study, participants received $50 €$ in advance, the maximum possible earnings. They were told that at the end of the study they would have to pay back the difference in actual earnings. Assuming the continuous base pay model where, for example, a participant earned a total of $42 €$ during the production phase, in the 
$50 €$ advance payment condition, they would have to pay back $8 €$ at the end if they missed the $90 \%$ criterion.

Bonus pay: In this condition, participants are told that they will receive a bonus if they achieve a total of $90 \%$ safety and productivity. The bonus is then an additional payment for rounding up to a full $50 €$. Following the example above, meeting $90 \%$ of the safety and productivity targets would pay a bonus of $8 €$ to reach $50 €$.

\subsection{Dependent Variable: Risk-Taking Behavior}

To create a situation that would allow risky behavior, we introduced a mandatory safety-related rule in the start-up procedure in the course of action of the production setting.

At the end of the first simulated quarter (Q1), that is, after the plant was already started up 12 times with a previously used procedure, participants were informed that an explosion occurred in another plant of the fictitious "Water Tech" company. As a result, the plant start-up procedure was altered. The training procedure in quarter 1, consisting of 10 substeps. Based on the events in the story of the intervention, 3 more substeps were added to the procedure to make the workflow safer. This intervention was followed by the training of the extended (and now safe) procedure (7) in Figure 2). This was followed by four trial runs in which the learned extension of the procedure was applied in practice and its knowledge was also recorded in a theoretical test. Successful performance in these tests was used as an inclusion criterion and a prerequisite for inclusion in the data analysis. In this way, we ensure that the rule violation operationalized as the dependent variable is not based on lack of knowledge, but on a conscious action.

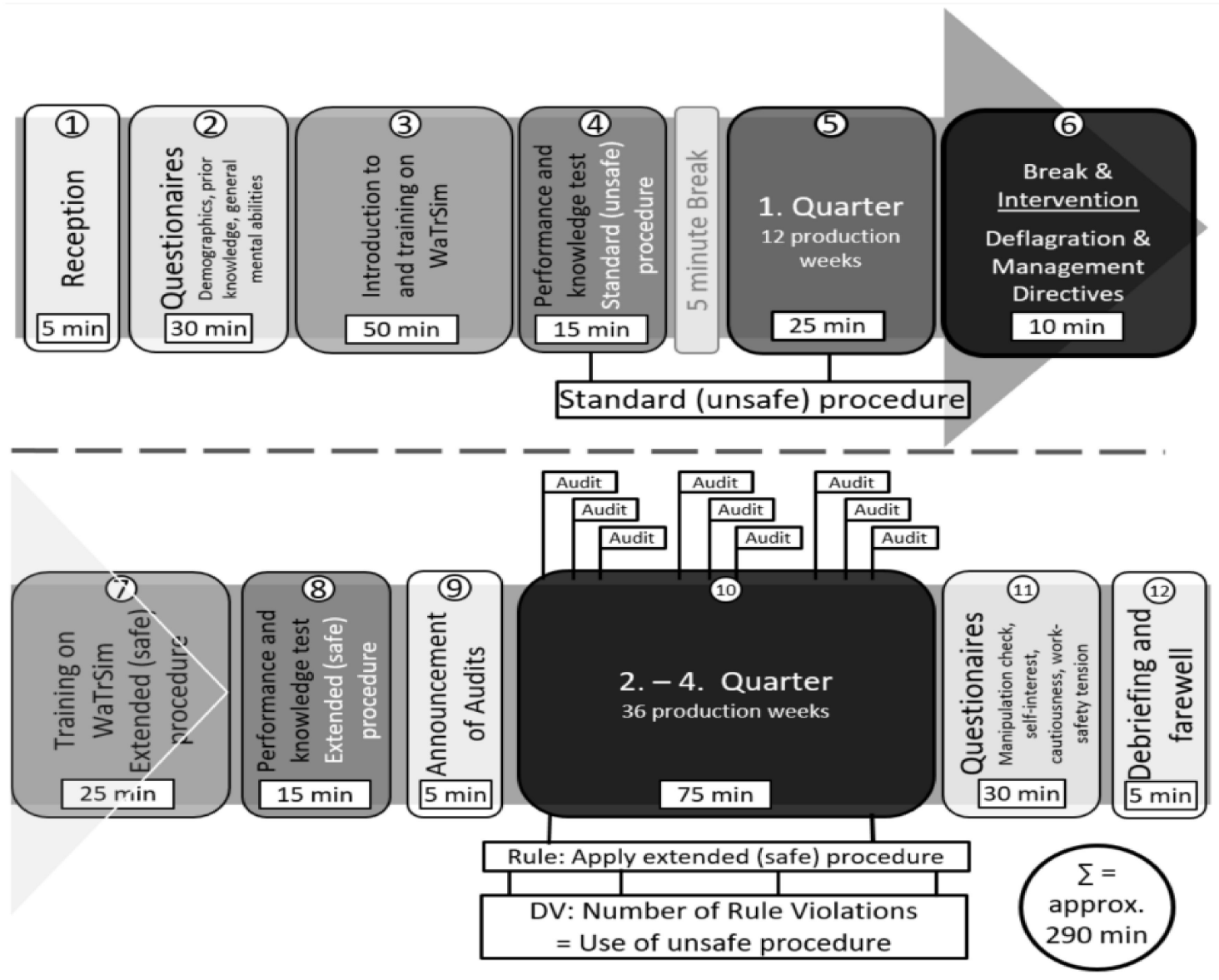

Figure 2. Phases and duration of experimental procedure, measurements taken, trained procedures and measurement of dependent variable of rule violation. 
By then, the extended (safer) procedure was declared mandatory, even if it took a bit longer to start up the plant, reducing the possible production outcome. From the beginning of the second quarter, earnings were calculated partly by effective production, but also by safe production. In Q1, earnings were defined solely by production output. With the new procedure, safety and productivity could be reconciled, even if it was a bit longer than the previous procedure. Compliance with the new rule was also assessed by announced audits. The simulation software logs which procedure the participants execute. If they do not follow the rule and continue to use the riskier procedure from the first quarter, it is counted as a rule violation. At the same time, in the three other quarters (36 stages), the system automatically conducts 9 audits. If there is a rule violation in the audited week, a penalty is applied by reducing the wage of the affected week to $0.00 €$.

The dependent variable, risk-taking, is therefore operationalized by the number of times the mandatory rule is not adhered to and the risk of causing an explosion. The score is the absolute number of times when participants do not adhere to the mandatory safetyrelated rule in Q2-Q4 (score 0-36).

\subsection{Control Variables: Demographic-, Cognitive-, and Person-Related Variables}

To analyze the question regarding the influence of financial incentive schemes on safety-related rule-following behavior, a content-related selection of them is presented here (Table 2).

In addition to the demographic data of age, gender, and study duration, cognitionrelated variables such as general mental ability and success learning the procedures were also collected as person-related variables. The "Knowledge of Safe and Unsafe Procedures" test consists of a formal description of the procedures with 5 blanks in the unsafe procedure and 7 blanks in the safe procedure to be filled in. The difference in the number of blanks results from a difference in the length of the procedures. We have tried to achieve a consistent ratio of blanks to content.

In addition, the person-related variables of self-interest and cautiousness were collected, as these showed correlations with rule-related behavior in previous studies. Since the incentive schemes have characteristics of gain and loss framing, the chronic regulatory focus accounts for the chronic disposition to lose or gain sensitive behavior.

Table 2. Questionnaires used to assess cognitive-, person-, and personality-related aspects as control variables.

\section{Variable}

General mental ability $(0-50)$

$$
\begin{aligned}
& \text { Knowledge of unsafe } \\
& \text { procedure }(0-5) \\
& \text { Knowledge of safe } \\
& \text { procedure (0-7) } \\
& \text { Self-interest (1-5) }
\end{aligned}
$$

Cautiousness (1-5)

Work-safety tension (1-5)

Description $\quad$ Measure

Wonderlic test [34], 50 items, $12 \mathrm{~min}$ limit

Knowledge test, 5 blanks to fill in, 1 pt. each correct fill Knowledge test, 7 blanks to fill in, 1 pt. each correct fill

$$
\begin{gathered}
8 \text { items with } 5 \text { point } \\
\text { Likert-scale [35] }
\end{gathered}
$$

High value indicates low cautiousness

Sensing tension between productivity and safety

7 item subscale with 5 point Likert scale [36]
Example Item (Translated; German Used for Questionnaire)

What is the next number in this series? 1-0.5-0.25-0.125-?

[Fill in blanks]

[Fill in blanks]

"Pursuing my interests is more important to me than being fair."

"Sometimes it excites me to do risky things just to feel the thrill."

"Sometimes it is necessary to deviate from safety regulations because of productivity." 


\subsection{Experimental Procedure}

Participants were recruited on the university campus and informed that could earn up to $50 €$ by participating in a production experiment. The emphasis in the communication was on performance-based pay independent of the actually applied incentive scheme. In fact, due to ethical reasons, all participants received $50 €$ at the end of the study, regardless of study condition or performance.

\subsubsection{Introduction and Pre-Intervention Phase}

At the beginning of the experiment (1) in Figure 2), which took approximately $5 \mathrm{~h}$, participants were welcomed, and an initial implicit language check was conducted in the form of a personal self-introduction. One of the participation preconditions was a good understanding of the German language, to comprehend the instructional materials for operating the production site. If communication problems were already apparent at this point, participation had to be ended prematurely.

After the introduction (2) in Figure 2), questionnaires on prior knowledge about wastewater treatment processes were collected. In addition, a test on general cognitive abilities. This was followed by an introduction to and training on WaTrSim (3) in Figure 2) which contains a description of the parts of the plant, as displayed in Figure 1 as delivery (ger. "Anlieferung"), homogenization (ger. "Homogenisierung"), cleaning in the separation coloumn (ger. "Reinigung") and storage (ger. "Zwischenlager"). Participants were taught how to operate the interface. First, individual system parts, such as valves, flow rates and column control were operated and practiced. Then the individual operating steps were put together to start up the plant successfully. Two stages of exploratory operation of the plant followed with the support of the test supervisors and a manual. Then two stages of an independent start-up with the manual. Another two stages without the manual, in which the participants demonstrated that they could start up the plant independently (4) in Figure 2). Then the first quarter started for production (5) in Figure 2).

\subsubsection{Intervention and Acquisition of the Dependent Variable}

After the simulated first 12 weeks, a break occurred during which participants were asked to leave the experimental room under a pretext (6 in Figure 2). During this time, experimenters distributed a newspaper article that participants found at their seats when they returned to the room. The article described an explosion that had occurred at a plant owned by the fictitious Water Tech company, and as a result the rule to start up the plant had been changed. This new regulation was presented and demonstrated by the experimenters (7) in Figure 2). For this, the participants had two further stages with the manual to practice and two stages without the manual (8) in Figure 2).

After the training, the participants were introduced to the compensation model implemented in their respective conditions. The upcoming compliance audits were announced (9) in Figure 2). In the following three quarters (10 in Figure 2), the new procedure was to be used in a total of 36 stages. Apart from breaks between quarters, there were no further interruptions. In each quarter three audits took place, that Three audits were carried out in each quarter. These are implemented in the software and check which procedure the participants have applied. Depending on compliance or violation of the rule, a message is displayed on the screen after the audited week, informing about the result and its consequences.

\subsubsection{Further Control Variables and Disclose Debriefing}

Subsequently, participants completed further questionnaires (11) in Figure 2), while the investigators pretended to prepare the payout. As described above, all participants received $50 €$ regardless of the experimental conditions. In the debriefing (12) in Figure 2), the subject of the experiment and the actual purpose of the study were disclosed and there was time for discussion and questions. In addition to confirming receipt of payment, participants also signed a confidentiality agreement. The purpose of this was to ensure that 
neither the actual subject of the experiment nor the lump-sum compensation, regardless of production output, became known potential participants.

\section{Results}

Before the analysis, we checked whether the participants had acquired the skills to start up the plant during the training. We determined this by means of knowledge tests after the completion of training in the respective procedure. We wanted to make sure that risky behavior was not based on a lack of knowledge but on a conscious choice. Among this sample, all 59 subjects could be included in the final analysis (age: $\mathrm{M}=21.27(\mathrm{SD}=3.27$ ); 22 female). Among the control variables, self-interest and work-safety tension showed a significant correlation, with higher self-interest being associated with more perceived work-safety tension (Table 3). Correlation results show that the risky behavior under investigation was not affected by the measured control variables.

Table 3. Correlation table of control and dependent variables.

\begin{tabular}{|c|c|c|c|c|c|c|c|c|}
\hline & M & SD & 1 & 2 & 3 & 4 & 5 & 6 \\
\hline Risky behavior/violation (1) & 2.78 & 4.96 & & & & & & \\
\hline General mental abilities (2) & 26.98 & 6.29 & -0.07 & & & & & \\
\hline Knowledge of risky/unsafe procedure (3) & 4.90 & 0.36 & 0.05 & 0.14 & & & & \\
\hline Knowledge of safe procedure (4) & 6.85 & 0.41 & -0.07 & 0.05 & 0.13 & & & \\
\hline Self-interest (5) & 2.20 & 0.81 & 0.10 & -0.16 & -0.02 & 0.02 & & \\
\hline Cautiousness (6) & 3.27 & 0.68 & 0.06 & -0.09 & 0.01 & -0.07 & -0.18 & \\
\hline Work-safety tension (7) & 2.47 & 0.84 & 0.08 & -0.02 & 0.12 & -0.03 & 0.45 * & 0.07 \\
\hline
\end{tabular}

Note: $n=59, * p<0.01$.

\section{Hypothesis Testing}

Statistical testing of the hypotheses was performed via ANOVA (analysis of variance). Figure 3 shows the mean number of violations in the three conditions.

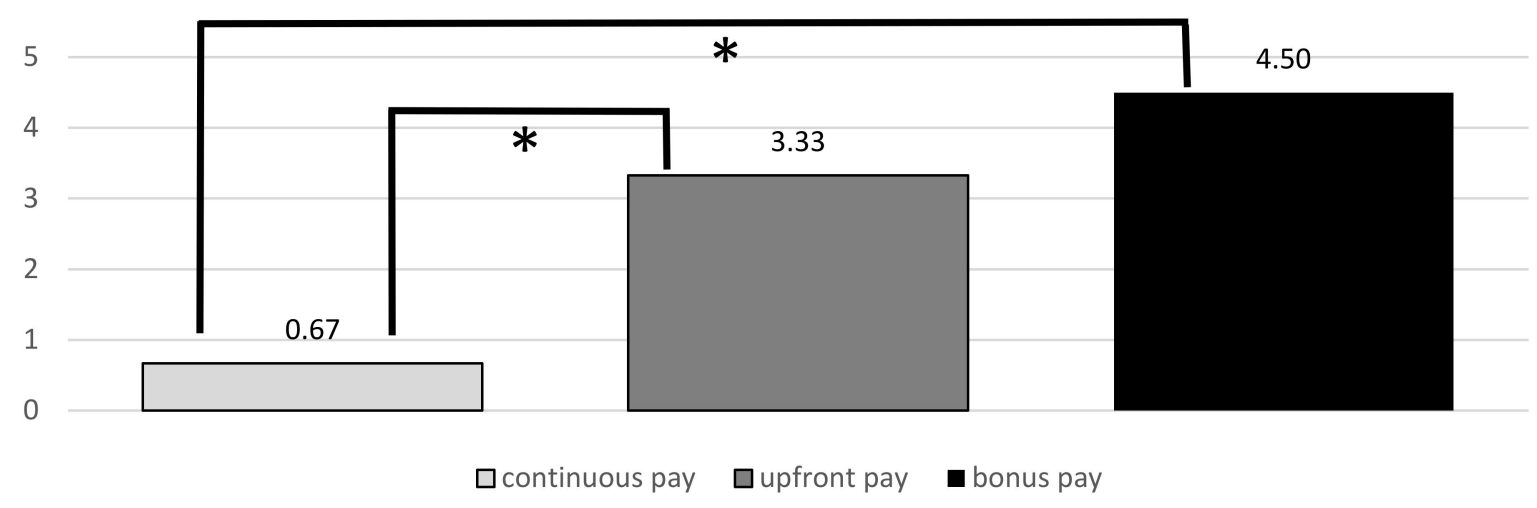

Figure 3. Mean number of risky behaviors/violations (0-36) in conditions of continuous, up-front, and bonus pay, highlighting significant differences between conditions. Note: ${ }^{*} p<0.05$.

Given the group size of the individual factors and the central limit theorem, we assume that the analysis results are robust to deviations from the normal distribution. As further preconditions, we examined whether the control variables correlated with the dependent variable and should thus be included in the analysis as covariates. Since none of the control variables are correlated with our dependent variable, analysis involving covariates is not indicated.

For hypothesis 1 (more risky behavior with bonus pay than with continuous pay), we found that bonus pay $(\mathrm{M}=4.50, \mathrm{SD}=6.81)$ leads to significantly more risky behavior than continuous pay $(\mathrm{M}=0.67, \mathrm{SD}=0.80)$, with an average difference of $3.82(\mathrm{SE}=1.53), p<0.05$, and a large effect size with $d=0.81$. 
For hypothesis 2 (more risky behavior with up-front payment than with continuous payment), the analysis shows that up-front payment $(\mathrm{M}=3.33, \mathrm{SD}=4.68)$ leads to significantly more risky behavior than continuous payment $(\mathrm{M}=0.67, \mathrm{SD}=0.80)$, with a mean difference of 2.67 ( $\mathrm{SE}=1.12), p<0.05$, and a medium to large effect size with $d=0.56$.

For hypothesis 3 (more risky behavior with bonus pay than with up-front pay), we found that bonus pay $(\mathrm{M}=4.50, \mathrm{SD}=6.81)$ and up-front pay $(\mathrm{M}=3.33, \mathrm{SD}=4.68)$ have an average difference of $-1.17(\mathrm{SE}=1.88)$ in terms of rule violations with $p=0.54$ and a small effect of $d=0.25$.

Hypotheses 1 and 2 are therefore considered to be supported, whereas hypothesis 3 is rejected.

This means that in the condition of continuous compensation, there is significantly less risky behavior in direct comparison with the bonus and up-front payment models. At the same time, bonus and up-front payments do not differ significantly from each other.

\section{Discussion}

The present study, to the best of our knowledge, represents the first experimental investigation on the impact of different financial incentive schemes on safety-related behavior in the simulated context of organizational rules. In particular, we aimed to highlight the effects of incentive schemes without the confounding influence of goal conflict. The goal conflict was specifically resolved in this study to avoid its risk-increasing effects. Therefore, it is particularly exciting to observe that by adding incentive schemes, risk behavior was at a similar level compared to studies with goal conflict without incentive schemes, found in our prior research [31]. In this study, too, it is clear that incentive schemes have a strong influence on risk behavior.

Hypotheses 1 and 2, which compare the incentive schemes of up-front and bonus payments with continuous compensation, showed significant differences with strong and medium to large effects in terms of increased risky behavior in terms of safety-related rule violations. We attribute the risk-increasing effect of explicit monetary incentive schemes to the emergence of an implicit internal goal conflict. Compared to the condition with no incentive system, bonus or up-front payment led to maximizing behaviors related to rule violations. In our study design, there was no goal conflict between productivity and safety. Thus, incentive schemes seemed to create the impression among individuals that they could maximize personal utility. This is where the differences between optimization and maximization come into play. If optimization is about benefits in relation to costs, this relativizing aspect is ignored in maximizing behavior. In this dynamic, the aspect of risk-taking is found again, in the form of the acceptance of possible disadvantages, i.e., the loss of the best possible cost/benefit ratio. Accordingly, a maximizing person hopes for additional benefits beyond the optimal point of proportionality.

The fact that the third hypothesis, which directly compares the effect of incentive schemes on rule-based behavior, does not reveal any significant differences could be explained by risk saturation. Since no goal conflict was included in the compensation modalities themselves, no compensation-relevant performance increase was possible through variations in behavior. Thus, in both conditions, subjects did not exceed a certain level of reward for risky behavior, since the utility-enhancing effect was absent.

The finding that incentives enhanced risky behavior is in line with the results of Stiglitz known for almost half a century [4]. Adding to this, we are able to show that no goal conflict was needed to create a risk rewarding context. The mere presence of an incentive scheme was enough to increase risk affinity, which confirms the ability of incentive schemes to circumvent rationality [13]. Neuroscientific research has shown a significant influence of reward anticipation on cognitive control, whereas this influence differs depending on task complexity, focus of reward, and the switch from rewarding to non-rewarding during the task [38-40]. Especially cognitive flexibility, which is associated with lower task maintenance and distractibility, is enhanced by switching reward prospects [38]. In our study, the $90 \%$ criterion was stable. Nevertheless, the achievability could change while 
performing the start-up procedures. This might support our finding that under incentive conditions more risk-taking behavior is shown than under stable no-incentive conditions. Our results do not show any effect of incentive timing with regard to up-front or bonus pay. We assumed this effect was in line with prospect theory's framing effect of loss and gain.

In addition, the person-related variables showed a correlation between self-interest and work-safety tension. In previous studies, work-safety tension was consistently shown to correlate with rule violations [24,31]. Thus, if a conflict between work and safety is perceived, rule violations can always be expected to increase. At the same time, self-interest was also shown to be a relevant aspect in connection with the typology of rule-related behavior [41], as soon as different behavioral strategies in dealing with rules are taken into account. This also explains why self-interest correlates with work-safety tension, but not generally with rule violations, since this correlation is type-related. In contrast, work-safety tension seems to have a general amplifying effect on rule violations.

\subsection{Strengths and Limitations}

When deciding between laboratory and field studies, the advantages and disadvantages of the respective variants must be weighed, but only if a choice is available at all. From an ethical perspective, the study context of increasing or decreasing safety-related rule violations by manipulating conditions cannot be conducted in a real-world setting. To maintain external validity, we selected only engineering students as potential workers in a safety-critical work context. However, this population is limited with regard to accessible number, so the sample size could not reach the optimal size, also due to time and financial constraints. However, in line with our prior studies [24,31], the sample size was sufficient to show medium to large effects.

With reference to the sample size and the achieved effect size, the power of the test indicates a $69.6 \%$ probability of avoiding the beta error. Accordingly, the rejected third hypothesis would at least have to consider the possibility that bonuses and up-front payments do make a significant difference. However, this is contradicted by the theoretical assumption that up-front payments represent loss framing and bonus payments represent gain framing. According to the framing effect, contrary to the findings of our study, significantly more rule violations should be observed with up-front payments than bonus payments. Therefore, we also see a theory-based argument to maintain the rejection of the third hypothesis.

\subsection{Further Research}

The complexity of the study series has allowed for the use of only a limited number of scales on personality aspects and other person-related aspects. Here, the study offers starting points for in-depth research of the influence of different personality and situational conditions on the effects of incentive schemes in terms of moderation and mediation models. Since the focus of the present study was on the fundamental effect mechanisms of incentive schemes compared with each other, person-related aspects (e.g., relevance of financial rewards and incentives) were within that focus and could not be dealt with in depth. In particular, the role of self-interest comes to the fore. It has so far been shown to be related to different behavioral strategies or, for example, Work-Safety Tension, but not isolated in the relationship with rule violations. This indicates that self-interest can have an impact on rule violations under certain conditions in certain contexts.

\subsection{Practical Implications}

As our findings show that incentive schemes increase risky behavior by their mere presence, their implementation must be carefully examined. If possible, goal conflicts between productivity and safety should be eliminated, without additional reward systems. If this is not possible, other research results show that incentivizing non-risky behavior can contribute to occupational safety. In the context of behavior-based safety management, incentive schemes emerge in our study as effective mechanisms for influencing behavior. 
As indicated in the cited literature and our research findings in this and previous studies, risk-related behavior can be influenced. Thus, practitioners have a known tool at their disposal that "only" needs to be used for safety. Since our results show strong effects, they provide an opportunity and reason to examine existing incentive systems for their effects on safety-related behavior. Likewise, apart from the available findings, studies on the perception of incentive systems at different hierarchical levels can be embedded in the context of evidence-based management. Ultimately, implicit structures, such as reputation and carrier concerns, also represent their own incentive systems.

\subsection{Outlook and Conclusions}

A work environment without goal conflict is theoretical. In the practice of industries with safety-critical activities, goal conflict is inevitable due to the omnipresent competitive pressure. Since we were able to show the basic effect of incentive schemes in our study, the question is how the dynamics play out with existing goal conflict. As long as the purpose of incentive schemes is to increase risk-taking, they will reinforce the risk-increasing effects of the tension between safety and productivity in favor of productivity. However, this is carried out at the expanse of safety. Further research will need to show whether safetyoriented incentive schemes can tip the scales in favor of safety. One mechanism in this regard could be a social security system such as unconditional basic income. As noted in the Introduction, a social security system can have the effect of further reinforcing the risk propensity of board members. At the same time, it can also give employees room to negotiate and make decisions regarding the conflict between productivity and security. Likewise, it could reduce the competitive pressure on the organization, which is basically just passed on to the workers.

Author Contributions: Conceptualization, A.K. and S.B.; methodology, A.K. and S.B.; software, A.K. and S.B.; validation, A.K. and S.B.; formal analysis, S.B.; investigation, S.B.; resources, A.K.; data curation, S.B.; writing—original draft preparation, S.B.; writing—review and editing, A.K. and S.B.; visualization, S.B.; supervision, A.K.; project administration, S.B.; funding acquisition, S.B. All authors have read and agreed to the published version of the manuscript.

Funding: This work was supported by the German Research Foundation under Grant KL2207/2-3.

Institutional Review Board Statement: The study was conducted according to the guidelines of the Declaration of Helsinki, and approved by the Institutional Ethics Committee of the Faculty of Psychology at Ruhr University Bochum (protocol No. 189, 18.02.2015).

Informed Consent Statement: Informed consent was obtained from all subjects involved in the study.

Data Availability Statement: The data presented in this study are available on request from the corresponding author. The data are not publicly available due to participants data protection policy.

Acknowledgments: We would like to thank the Ruhr-University Bochum for its support and cooperation, as well as the university alliance partners TU Dortmund and University Duisburg-Essen for providing facilities to acquire and conduct the study. In particular, we would like to thank Merle Lau, Lina Kluy, Felix Miesen, Pia Schempp, Leonie Kloep, Maike Puhe, and Lena Iffland, who were conscientiously and persistently involved in data collection and data maintenance over the years. For the competent and patient extension of our WaTrSim software we thank Kathrin Bischof. We are especially grateful for the appreciative and constructive support of the German Research Foundation (DFG).

Conflicts of Interest: The authors declare no conflict of interest. 


\section{References}

1. McMahon, J. Transocean Execs Get Bonuses after 'Best Year in Safety', Despite Gulf Oil Disaster. Forbes. 2 April 2011. Available online: https:/ /www.forbes.com/sites/jeffmcmahon/2011/04/02/transocean-bonuses-deepwater-horizon-gulf-spill/ (accessed on 29 January 2021).

2. Vetter, P. Mit Einem Trick Genehmigen Sich Die VW-Vorstände Doch Noch Ihren Bonus. Welt. 12 January 2017. Available online: https:/ / www.welt.de/wirtschaft/article161127513/Mit-einem-Trick-genehmigen-sich-die-VW-Vorstaende-doch-nochihren-Bonus.html (accessed on 29 January 2021).

3. Mendelez, E.D. Financial Crisis Cost Tops $\$ 22$ Trillion, GAO Says. Available online: https://www.huffpost.com/entry/financialcrisis-cost-gao_n_2687553? (accessed on 22 January 2021).

4. Stiglitz, J.E. Incentives, Risk, and Information: Notes Towards a Theory of Hierarchy. Bell J. Econ. 1975, 6, 552. [CrossRef]

5. Kreilkamp, N.; Matanovic, S.; Schmidt, M.; Wöhrmann, A. How Incentive System Design Affects Risk-Taking: A Literature Review. SSRN J. 2019, 91, 19. [CrossRef]

6. Dodoo, J.E.; Al-Samarraie, H. Factors leading to unsafe behavior in the twenty first century workplace: A review. Manag. Rev. Q. 2019, 69, 391-414. [CrossRef]

7. Dittmann, I.; Yu, K.-C.; Zhang, D. How Important Are Risk-Taking Incentives in Executive Compensation? Rev. Financ. 2017, 21, 1805-1846. [CrossRef]

8. Çitçi, S.H. Incentive Roots of Managerial (Excessive) Risk Taking and an Assesment of Policy Responses. Int. Rev. Econ. Manag. 2016, 4, 29-44. [CrossRef]

9. Ellul, A.; Wang, C.; Zhang, K. Labor Unemployment Risk and CEO Incentive Compensation. SSRN J. 2015, 108, 141. [CrossRef]

10. Neves, P.; Eisenberger, R. Perceived organizational support and risk taking. J. Manag. Psychol. 2014, 29, 187-205. [CrossRef]

11. Pfeiffer, L.; Gratz, T. The effect of rights-based fisheries management on risk taking and fishing safety. Proc. Natl. Acad. Sci. USA 2016, 113, 2615-2620. [CrossRef]

12. Karakhan, A.; Gambatese, J. Hazards and Risk in Construction and the Impact of Incentives and Rewards on Safety Outcomes Pract. Period. Struct. Des. Constr. 2018, 23, 4018005. [CrossRef]

13. de Walque, D. The use of financial incentives to prevent unhealthy behaviors: A review. Soc. Sci. Med. 2020, $261,113236$. [CrossRef]

14. Stone-Romero, E.F. Research strategies in industrial and organizational psychology: Nonexperimental, quasi-experimental, and randomized experimental research in special purpose and nonspecial purpose settings. In APA Handbook of Industrial and Organizational Psychology, Vol 1: Building and Developing the Organization; Zedeck, S., Ed.; American Psychological Association: Washington, DC, USA, 2011; pp. 37-72. ISBN 1-4338-0732-7.

15. McLain, D.L.; Jarrell, K.A. The perceived compatibility of safety and production expectations in hazardous occupations. J. Saf. Res. 2007, 38, 299-309. [CrossRef] [PubMed]

16. Mattson, M.; Torbiörn, I.; Hellgren, J. Effects of staff bonus systems on safety behaviors. Hum. Resour. Manag. Rev. 2014, 24, 17-30. [CrossRef]

17. Kahneman, D.; Tversky, A. Prospect Theory: An Analysis of Decision under Risk. Econometrica 1979, 47, 263-292. [CrossRef]

18. Essl, A.; Jaussi, S. Choking under time pressure: The influence of deadline-dependent bonus and malus incentive schemes on performance. J. Econ. Behav. Organ. 2017, 133, 127-137. [CrossRef]

19. Fryer, R.; Levitt, S.; List, J.; Sadoff, S. Enhancing the Efficacy of Teacher Incentives through Loss Aversion: A Field Experiment; National Bureau of Economic Research: Cambridge, MA, USA, 2012.

20. Hossain, T.; List, J.A. The Behavioralist Visits the Factory: Increasing Productivity Using Simple Framing Manipulations. Manag. Sci. 2012, 58, 2151-2167. [CrossRef]

21. Luft, J. Bonus and penalty incentives contract choice by employees. J. Account. Econ. 1994, 18, 181-206. [CrossRef]

22. Church, B.K.; Libby, T.; Zhang, P. Contracting Frame and Individual Behavior: Experimental Evidence. J. Manag. Account. Res. 2008, 20, 153-168. [CrossRef]

23. Hannan, R.L.; Hoffman, V.B.; Moser, D.V. Bonus versus Penalty: Does Contract Frame Affect Employee Effort. In Experimental Business Research; Rapoport, A., Zwick, R., Eds.; Springer: Berlin/Heidelberg, Germany, 2005; pp. 151-169. ISBN 0-387-24214-7.

24. Brandhorst, S.; Kluge, A. When the Tension Is Rising: A Simulation-Based Study on the Effects of Safety Incentive Programs and Behavior-Based Safety Management. Safety 2021, 7, 9. [CrossRef]

25. Imas, A.; Sadoff, S.; Samek, A. Do People Anticipate Loss Aversion? Manag. Sci. 2017, 63, 1271-1284. [CrossRef]

26. de Quidt, J. Your Loss Is My Gain: A Recruitment Experiment with Framed Incentives. J. Eur. Econ. Assoc. 2018, 16, 522-559. [CrossRef]

27. Hilken, K.; Rosenkranz, S.; de Jaegher, K.; Jegers, M. Reference Points, Performance and Ability: A Real Effort Experiment on Framed Incentive Schemes; Discussion Paper Series No. 13-15; Utrecht School of Economics: Utrecht, The Netherlands, 2013.

28. Grolleau, G.; Kocher, M.G.; Sutan, A. Cheating and Loss Aversion: Do People Cheat More to Avoid a Loss? Manag. Sci. 2016, 62, 3428-3438. [CrossRef]

29. Von der Heyde, A.; Brandhorst, S.; Kluge, A. The impact of the accuracy of information about audit probabilities on safety-related rule violations and the bomb crater effect. Saf. Sci. 2015, 74, 160-171. [CrossRef]

30. Von der Heyde, A.; Brandhorst, S.; Kluge, A. The impact of safety audit timing and framing of the production outcomes on safety-related rule violations in a simulated production environment. Saf. Sci. 2015, 77, 205-213. [CrossRef] 
31. Brandhorst, S.; Kluge, A. Unintended Detrimental Effects of the Combination of Several Safety Measures-When More Is Not Always More Effective. Safety 2021, 7, 37. [CrossRef]

32. Burkolter, D.; Kluge, A.; German, S.; Grauel, B. Waste Water Treatment Simulation (WaTr Sim): Validation of a New Process Control Simulation Tool for Experimental Training Research. Proc. Hum. Factors Ergon. Soc. Annu. Meet. 2009, 53, 1969-1973. [CrossRef]

33. Brandhorst, S.; Kluge, A. The bomb crater effect under the influence of audit feedback: Now you see me, now you don't. Saf. Sci. 2018, 110, 449-456. [CrossRef]

34. Wonderlic, E.F. Wonderlic Personnel Test; Wonderlic, Inc.: Libertyville, IL, USA, 2002.

35. Mohiyeddini, C.; Montada, L. "Eigeninteresse" und "Zentralität des Wertes Gerechtigkeit für eigenes Handeln": Neue Skalen zur Psychologie der Gerechtigkeit. "Self-Interest" and "Centrality of the Value of Justice for One's Own Actions": New Scales on the Psychology of Justice; Universität Trier: Trier, Germany, 2004.

36. Marcus, B. Tests und Tools. Z. Für Pers. 2007, 6, 129-132. [CrossRef]

37. Stride, C.B.; Turner, N.; Sandy Hershcovis, M.; Reich, T.C.; Clegg, C.W.; Murphy, P. Negative safety events as correlates of work-safety tension. Saf. Sci. 2013, 53, 45-50. [CrossRef]

38. Chiew, K.S. Revisiting positive affect and reward influences on cognitive control. Curr. Opin. Behav. Sci. 2021, 39, 27-33. [CrossRef]

39. Boehler, C.N.; Schevernels, H.; Hopf, J.-M.; Stoppel, C.M.; Krebs, R.M. Reward prospect rapidly speeds up response inhibition via reactive control. Cogn. Affect. Behav. Neurosci. 2014, 14, 593-609. [CrossRef]

40. Krebs, R.M.; Woldorff, M.G. Cognitive Control and Reward. In The Wiley Handbook of Cognitive Control; Egner, T., Ed.; John Wiley \& Sons, Ltd.: Chichester, UK, 2017; pp. 422-439. ISBN 9781118920497.

41. Brandhorst, S.; Kluge, A. The Spectrum of Safety-Related Rule Violations. J. Cogn. Eng. Decis. Mak. 2016, 10, 178-196. [CrossRef] 